\title{
OPEN
}

Published online: 13 February 2020

\section{Author Correction: Relationship between body mass index and renal function deterioration among the Taiwanese chronic kidney disease population}

\begin{abstract}
Tian-Jong Chang, Cai-Mei Zheng, Mei-Yi Wu, Tzu-Ting Chen, Yun-Chun Wu $\mathbb{D}$, Yi-Lien Wu, Hsin-Ting Lin, Jing-Quan Zheng, Nain-Feng Chu, Yu-Me Lin, Sui-Lung Su, Kuo-Cheng Lu, Jin-Shuen Chen, Fung-Chang Sung, Chien-Te Lee, Yu Yang, Shang-Jyh Hwang, MingCheng Wang, Yung-Ho Hsu, Hung-Yi Chiou, Senyeong Kao \& Yuh-Feng Lin
\end{abstract}

Correction to: Scientific Reports https://doi.org/10.1038/s41598-018-24757-6, published online 02 May 2018

The original version of this Article contained an error in Affiliation 3, which was incorrectly given as 'Department of Internal Medicine, School of Medicine, College of Medicine, Taipei Medical University, Taipei, Taiwan' The correct affiliation is listed below:

Division of Nephrology, Department of Internal Medicine, School of Medicine, College of Medicine, Taipei Medical University, Taipei, Taiwan

This error has now been corrected in the HTML and PDF versions of the Article.

\begin{abstract}
(c) (i) Open Access This article is licensed under a Creative Commons Attribution 4.0 International License, which permits use, sharing, adaptation, distribution and reproduction in any medium or format, as long as you give appropriate credit to the original author(s) and the source, provide a link to the Creative Commons license, and indicate if changes were made. The images or other third party material in this article are included in the article's Creative Commons license, unless indicated otherwise in a credit line to the material. If material is not included in the article's Creative Commons license and your intended use is not permitted by statutory regulation or exceeds the permitted use, you will need to obtain permission directly from the copyright holder. To view a copy of this license, visit http://creativecommons.org/licenses/by/4.0/.
\end{abstract}

(C) The Author(s) 2020 